\title{
The International Urogynaecology Consultation: the new IUGA educational project
}

\author{
Alex Digesu $^{1} \cdot$ Steven Swift ${ }^{2}$ \\ Received: 14 July 2021 / Accepted: 14 July 2021 / Published online: 6 August 2021 \\ (C) The International Urogynecological Association 2021
}

This editorial is to introduce The International Urogynaecology Consultation (IUC) as a new multi-year project endorsed and approved by the International Urogynaecology Association (IUGA). The goal is to produce a series of review manuscripts on pelvic organ prolapse (POP) [1-6]. In this edition of the International Urogynecology Journal, we present the first two narrative reviews: (1) International Urogynecological Consultation (IUC): Clinical definition of Pelvic Organ Prolapse (POP) and (2) International Urogynecology Consultation: Relationship of Pelvic Organ Prolapse to Associated Pelvic Floor Dysfunction Symptoms: Lower Urinary Tract, Bowel, Sexual Dysfunction and Abdominopelvic Pain.

This consultation will be a 4-year project producing a collection of 16 narrative review articles bringing together the most up-to-date scientific evidence to assist IUGA members in their clinical practice, inspire their research and provide best practice documents. The manuscripts will be published in the International Urogynecology Journal, as they are completed and peer-reviewed. Once all 16 manuscripts have been completed and published, they will be part of IUGA e-book.

The governance structure for this consultation involves two Consultation chairs (AD and SS) and a Steering Committee composed of seven IUGA key opinion leaders in different areas of female pelvic medicine. This group was selected by the IUGA executive committee. The steering committee, in concert with the two consultation chairs, selected, or will select, the 16 individual writing group chairs. The individual members of the writing groups were, and will be, selected through an open competitive application process utilizing atlarge members of IUGA. The writing group chairs were

Alex Digesu

a.digesu@imperial.ac.uk

1 St Mary's Hospital, Imperial College NHS Trust, London, UK

2 Medical University of South Carolina, Charleston, SC, USA responsible for selecting the $8-10$ at-large IUGA members in consultation with the two consultation chairs. The writing group chairs and members were, and will be, carefully vetted based on their experience with an additional goal of looking to establish a broad geographic representation.

At the 2018 IUGA annual meeting in Vienna, the coconsultation chairs (AD and SS) and steering committee members met for 1 day prior to the annual meeting to establish the topics for each of the 16 writing groups. The goal was to have approximately $3-5$ writing groups established each year beginning in 2019 to cover related topics on pelvic organ prolapse.

The topic for the first year to be covered by the IUC is the epidemiology of pelvic organ prolapse. It is composed of five writing groups: (1) the definition of POP, (2) the incidence, prevalence and natural history of POP, (3) the patients' perception of the disease of POP, (4) the pathophysiology of POP and (5) associated pelvic floor disorder symptoms. The writing group chairs were presented at the 2019 IUGA annual meeting in Nashville, Tn. This was the first open meeting of the IUC and each writing group chair presented his/her project and objective in a public forum to the IUGA society at large. This allowed an open discussion and public feedback, which was considered mandatory prior to the final writing and submission of the manuscripts for publication of the first section of IUC project, which will occur by the end of 2021. In 2020, the writing group chairs again presented their findings at the virtual IUGA annual meeting to receive feedback from the IUGA membership at large.

The other three themes the IUC will cover in the following years are: second year: assessment of POP; third year: conservative management of POP; fourth year: surgical management of POP. These working groups are still in various phases of development and data abstraction and will follow the same standard operating procedure. After the initial manuscript is developed by the writing groups it is reviewed by the two IUC Chairs ( $\mathrm{SS}$ and $\mathrm{AD}$ ) and sent back to the committees for revision. The manuscript is then sent to the IUC steering committee 
members for review and sent back to the committee chairs for revision. Next, the manuscripts are placed on the IUGA website for public feedback and comments and again returned to the committee chairs for revision. Finally, the IUGA executive board reviews the manuscripts before submission to the International Urogynecology Journal for formal peer review and revision before any are published.

We hope the IUC manuscripts will help our readership and membership with a series of narrative review articles. These articles will cover the breadth of pelvic organ prolapse, with the goal of collating the current knowledge of POP, improving the understanding of POP, helping define the deficits in our knowledge of POP and further promoting the international leadership role of IUGA in Urogynecology.

Author's contribution SS: manuscript writing, approval of final version. $\mathrm{AD}$ : manuscript writing, approval of final version.

\section{Declarations}

Conflict of interest AD: paid travel expenses, payment for research, consultant, position of influence in professional society ICS, IUGA, Bluewind, Medtronic, Allergan, Astellas, Pfizer.

SS: paid travel expenses, payment for research, consultant, position of influence in professional society AUGS, IUGA, Cook Myosite.

\section{References}

1. Samimi P, Jones SH, Giri A. Family history and pelvic organ prolapse: a systematic review and meta-analysis. Int Urogynecol J. 2020. https:// doi.org/10.1007/s00192-020-04559-z Online ahead of print.

2. Carlin GL, Bodner-Adler B, Husslein H, Ritter M, Umek W. The effectiveness of surgical procedures to prevent post-hysterectomy pelvic organ prolapse: a systematic review of the literature. Int Urogynecol J. 2020. https://doi.org/10.1007/s00192-020-04572-2 Online ahead of print.

3. Siahkal SF, Iravani M, Mohaghegh Z, Sharifipour F, Zahedian M, Nasab MB. Investigating the association of the dimensions of genital hiatus and levator hiatus with pelvic organ prolapse: a systematic review. Int Urogynecol J. 2021. https://doi.org/10.1007/s00192020-04639-0 Online ahead of print.

4. Teixeira FH, Fernandes CE, Do Souto RP, de Oliveira E. Polymorphism rs1800255 from COL3A1 gene and the risk for pelvic organ prolapse. Int Urogynecol J. 2020;31(1):73-8. https://doi. org/10.1007/s00192-019-03965-2.

5. Developed by the Joint Writing Group of the American Urogynecologic Society and the International Urogynecological Association. Joint report on terminology for surgical procedures to treat pelvic organ prolapse. Int Urogynecol J. 2020;31(3):429-63. https://doi.org/10.1007/s00192-020-04236-1.

6. Muñiz KS, Voegtline K, Olson S, Handa V. The role of the genital hiatus and prolapse symptom bother. Int Urogynecol J. 2020. https:// doi.org/10.1007/s00192-020-04569-x Online ahead of print.

Publisher's note Springer Nature remains neutral with regard to jurisdictional claims in published maps and institutional affiliations. 